\title{
Estudo Preliminar da Bioincrustação Sobre Substratos Naturais, COMO INDICADOR DE IMPACTO NA REGIÃO DO COMPLEXO PORTUÁRIO DE SUAPE-PE.
}

\author{
ANDRÉA KARLA PEREIRA DA SILVA ${ }^{1}$ \\ ELGA MIRANDA MAYAL ${ }^{2}$ \\ ROSA DE LIMA SILVA MELLO ${ }^{3}$ \\ MÚCIO LUIZ BANJA FERNANDES ${ }^{4}$
}

1 - Depto. Oceanografia, Bolsista da FACEPE

2 - Depto. Zoologia - UFPE

3 - Depto. De Pesca - UFRPE

4. -FFPNM - UPE, UNESF-FUNESO

\begin{abstract}
RESUMO
O presente trabalho teve como objetivo identificar a composição faunística e florística incrustantes do recife arenítico da região do Porto de Suape, PE, bem como acompanhar o desenvolvimento desses grupos sobre este tipo de substrato, analisando o processo de sucessão ecológica do mesmo, sob as condições ambientais ao qual estão expostos. Este estudo foi realizado durante o período de julho a dezembro de 1998, através do acompanhamento bimestral da recolonização sobre uma superfície recifal previamente preparada, com dimensões e posicionamento predeterminados, em regiões do mediolitoral. Durante os seis meses de acompanhamento, observou-se que os primeiros macrocolonizadores estiveram representados pelas algas filamentosas verdes e pardas, com desenvolvimento significativo nos pontos sujeitos a períodos de inundação mais prolongados, e com baixa taxa de sedimentação (porção externa e média do recife). Nos pontos localizados na porção interna do recife, não foram identificados nenhuma evolução nas incrustações, devido às elevadas taxas de sedimentação ocasionadas pelos processos de dragagens no interior da baía de Suape por ocasião da ampliação do seu Complexo Portuário.
\end{abstract}

Palavras chave: Bioincrustação, recifes, sucessão ecológica, bentos

\section{ABstract \\ Preliminar Study of the Bioincrustration on Natural Substrates, as Impacts Indicator at Suape Port Complex, PE.}

The present work had as objective identifies the fauna and flora composition of the beachrocks fouling at the Port of Suape, PE, and to follow the development of these groups on this type of substratum. The ecological succession was analyzed under the port influence. The study was carried out from July to December/1998. Bimonthly observations were taken on a reef surface previously measured and marked. During the six months it was observed that the first macrocolonizers were the green and brown algae, which quickly grew in flooded areas with low sedimentation (external and medium area of the reef). In the internal area of the reef, no fouling occurred during the studied period, due to high sedimentation tax caused by the port dredging inside Suape Bay for the implantation of an internal port.

Key words: Bioincrustation, reefs, sucession, benthos 


\section{INTRODUÇÃO}

As comunidades incrustantes, constituem organismos bentônicos que se fixam sobre substratos consolidados naturais e artificiais e são também designadas pelo termo "fouling". De acordo com Giordano (2001) os trabalhos clássicos sobre sucessão ecológica em comunidades bentônicas no mundo, enfatizam a diversidade das comunidades já estabelecidas. Outros, ainda dão ênfase às estratégias de ocupação do substrato pelas larvas. Em qualquer uma dessas linhas de pesquisa, as características ambientais de cada local determinam composição e abundância dessas comunidades incrustantes. Diversos fatores físicos e biológicos podem influenciar o desenvolvimento de aderências orgânicas sobre um substrato. Dentre os fatores físicos, Straughan (1967) verificou que a salinidade atua diretamente na distribuição das espécies e fixação das larvas, como também na mortalidade de indivíduos mais velhos. Silva et al. (1980) apontam a temperatura como elemento determinante do tipo de incrustação, afirmando que regiões mais quentes apresentam maior riqueza de fauna e flora incrustantes. Steneck e James (2000) apontam as atividades humanas como responsáveis por alterações profundas nas comunidades incrustantes, principalmente por ocasionarem o desaparecimento de espécies nativas, invasão de espécies exóticas, poluição química, eutrofização, toxicidade por "blooms” de fitoplâncton, alterações físicas nos habitats, além de mudanças climáticas globais. Neste contexto, o estudo da comunidade de organismos incrustantes tem se revelado de fundamental importância, visto que constitui, junto com os sedimentos, a base das edificações dos recifes em águas tropicais. Sobre substratos artificiais, estes organismos podem danificar estruturas submersas, obstruir tubulações e até reduzir a velocidade de embarcações.

Em várias localidades, estudos referentes a colonizações sobre substratos duros marinhos vêm sendo realizados com o intuito de verificar os mecanismos e padrões de sucessão e desenvolvimento desse tipo de comunidade em áreas de forte influência antrópica, utilizando-a como indicadores de impacto ambiental. Para Fernandes (2000), atualmente, assinala-se a construção e ampliação do Porto de Suape como a maior obra humana impactante para a região costeira do Estado de Pernambuco. Sucessivas dragagens objetivando o aumento de profundidade no porto interno disponibilizam elevadas taxas de sedimento e material particulado elevando a turbidez da água e condicionando características especiais na região.

Para Silva et al (1980), a diversidade das comunidades incrustantes bem como a sua biomassa variam de acordo com as condições ambientais de cada local. Nas regiões tropicais, onde a temperatura das águas é mais elevada e com pouca variação sazonal, quando comparada com águas de regiões temperadas, observa-se um contínuo processo de colonização por parte dos organismos incrustantes, o que proporciona uma rápida sucessão ecológica e, conseqüentemente, uma elevada biomassa.

Coe (1937) considera o espaço para fixação um dos fatores limitantes para as espécies sésseis, onde freqüentemente existe uma espécie que é competidora dominante, capaz de excluir as outras espécies. Os distúrbios físicos e biológicos minimizam a competição por espaço, prevenindo a monopolização deste por uma única espécie, aumentando a sua diversidade na comunidade. Quanto aos distúrbios de origem biológica que podem interferir numa comunidade incrustante, Dayton (1971) considerou a atividade dos herbívoros raspadores (ouriços) e a predação como os distúrbios biológicos mais importantes no ambiente marinho, principalmente no infralitoral.

Ortega (1981) trabalhando com a comunidade incrustante de zonas entre marés da Carolina do Norte, observou que as espécies dominantes em um substrato variam de acordo com o grau de exposição à ondas. Neste trabalho, o autor verificou que as ostras constituem espécies dominantes em áreas mais abrigadas, enquanto que em áreas mais expostas à ação das ondas, observa-se que cracas, mexilhões e algas constituem os grupos mais freqüentemente encontrados. Este panorama descrito pelos autores acima pode ser considerado também para a região dos recifes de Suape. 
O presente trabalho, visa identificar a composição faunística e florística incrustantes do recife arenítico de Suape - PE, bem como acompanhar o desenvolvimento desses grupos sobre o recife, estabelecendo o processo de sucessão ecológica do mesmo, de acordo com as condições abióticas ao qual estão expostos, de modo a que no futuro possa se avaliar o efeito dos impactos da construção do Porto de Suape sobre a formação recifal.

\section{MATERIAIS E MÉTODOS}

A morfologia costeira da área de Suape se caracteriza-se por uma baía separada do mar aberto por um extenso cordão de recife de arenito, paralelo a linha de Costa, cuja extremidade norte apresenta uma barra de 800 metros de largura que faz a ligação da baía com o mar. No lado externo do recife a profundidade alcança a isóbata de $-13 \mathrm{~m}$, aumentando gradativamente para leste e alcançando cotas de $-18 \mathrm{~m}$. Na área interna da linha dos recifes, as profundidades eram menores, variando entre 2 e 5 metros. O cordão de recife que forma a baía de Suape é constituído por um banco de arenito, repousando sobre camadas de areia de textura variada, passando nos horizontes inferiores a sedimentos sílticos-argilosos (Fernandes, 2000).

Os estudos foram realizados, bimestralmente, de julho a dezembro de 1998, durante as baixa-mares diurnas, em um recife de arenito emerso. O recife localizava-se próximo às obras de ampliação do complexo portuário, onde em 1997 foram iniciadas as obras de construção do porto interno levando a abertura de um novo canal de passagem de navios por implosões e aumento da profundidade no local, de uma média de $5 \mathrm{~m}$ para de $20 \mathrm{~m}$. Para manutenção desta profundidade, a bacia de Suape passa hoje por constantes dragagens para permitir a entrada dos grandes navios que ali aportarão.

Transeções foram posicionadas ao longo dos perfis I e II (figura 1) na extensão norte dos recifes, sendo o primeiro próximo ao novo canal de navegação, recentemente construído, e o segundo $100 \mathrm{~m}$ ao norte deste. Foram escolhidos, visualmente, seis pontos, três em cada perfil, para preparação das áreas de acompanhamento, nas porções interna, média e externa do recife, durante o período estudado. As áreas apresentaram dimensões de $20 \mathrm{~cm}$ x $20 \mathrm{~cm}$ e foram limitadas por um quadrado de acrílico no momento das observações durante o experimento, e apresentavam os padrões de composição da fauna e flora incrustante semelhantes às áreas adjacentes, não apresentando indícios de coleta nem raspagens anteriores, estando todos localizados em porção de mediolitoral.

Uma vez estabelecidas as áreas de amostragem, utilizou-se pinos de aço como marcadores e cordas para facilitar a localização dos pontos na ocasião de visitas posteriores. Cada área de acompanhamento sofreu um processo de preparação para o início dos trabalhos quando foram raspadas com o auxilio de escova de aço, espátulas, escopos e martelo, a fim de eliminar qualquer vestígio da macrofauna e flora incrustantes já instaladas.

Os pontos situados na porção interna do recife, estiveram localizados no médiolitoral inferior, em regiões abrigadas, com superfície plana, moderadamente inclinada, protegidas da exposição direta dos raios solares, rodeadas por blocos de arenito maiores (fixos ou soltos), próximos de locas e reentrâncias.

As áreas da porção média do recife apresentam-se com exposição direta dos raios solares, ao nível da superfície do recife. No perfil II, o ponto da área do meio do recife foi representado por um bloco solto de arenito, com superfície completamente limpa e seca. Sobre esse bloco separouse uma área com dimensões padronizadas para este estudo, que permaneceu no mesmo nível médiolitoral superior do recife, semelhante a área mediana do perfil I, sujeitos à exposição direta da luz, vento e efeito das ondas durante a preamar.

Os pontos escolhidos na área externa do recife apresentavam características semelhantes: sobre uma área plana relativamente inclinada, desabrigada e sujeita a forte influência do batimento das ondas, mesmo durante a maré baixa.

Tropical Oceanography, Recife: v. 29, n. 2, p. 139-146, 2001. 


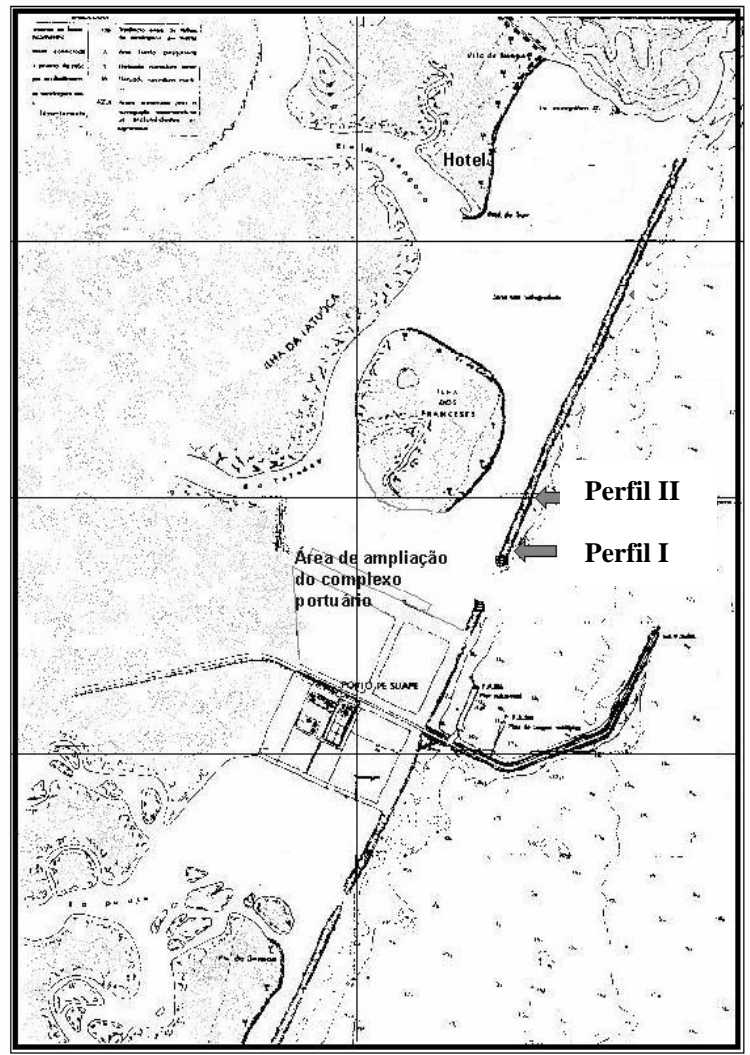

Figura 01 - Localização dos Perfis I e II sobre o recife arenítico de Suape, $\mathrm{PE}$, onde foram demarcadas as áreas de observação interna, média e externa.

Cada área estabelecida para acompanhamento foi marcada com GPS (Global Position of System). As observações ocorreram de dois em dois meses quando cada ponto foi analisado quanto as modificações sofridas na sua cobertura. Estudos paralelos sobre a composição biológica do recife foram realizados, determinando sua riqueza e diversidade.

Por ocasião de cada visita realizada, tomou-se o cuidado de observar o recobrimento em cada ponto de amostragem, identificando os organismos fixados. Amostras das mesmas espécies que passaram a recobrir os pontos de acompanhamento foram recolhidas para posterior

identificação sistemática, definindo, também, a posição de cada táxon dentro do processo de sucessão ecológica, identificando os colonizadores primários secundários, terciários e assim, sucessivamente. 


\section{RESUltados E Discussão}

O quadro esquemático a seguir sintetiza os resultados obtidos e revela os índices de ocorrência dos organismos incrustantes através do seu percentual de cobertura, sendo considerados como Freqüentes (F) os organismos incrustantes com cobertura maior que $70 \%$, pouco freqüentes (P) para ocorrência entre 35\% e 70\%, raros (R) para organismos com percentuais de cobertura inferiores a 35\% e ausentes (A) para o caso de inexistência do organismos no momento da observação.

Quadro esquemático dos resultados obtidos no estudo do desenvolvimento das bioincrustacoes sobre o recife arenitico de Suape, realizado durante o período de julho a dezembro de 1998.

\begin{tabular}{|c|c|c|c|c|c|c|}
\hline \multirow{2}{*}{$\begin{array}{l}\text { FAUNA E FLORA } \\
\text { INCRUSTANTES E } \\
\text { SEDENTÁRIAS }\end{array}$} & \multicolumn{3}{|c|}{ LOCALIZAÇÃO } & \multicolumn{3}{|c|}{ PERÍODO } \\
\hline & INTERIOR & MEIO & EXTERIOR & $\begin{array}{c}\mathbf{1}^{\mathrm{o}} . \\
\text { BIMESTRE } \\
\text { I M E }\end{array}$ & $\begin{array}{c}2^{0} . \\
\text { BIMESTRE } \\
\text { I M E }\end{array}$ & $\begin{array}{c}3^{\circ} . \\
\text { BIMESTRE } \\
\text { I M E }\end{array}$ \\
\hline Algas verdes & $\mathrm{R}$ & F & F & A P F & R P F & A F F \\
\hline Algas pardas & $\mathrm{R}$ & A & $\mathrm{F}$ & A A A & A A P & A R F \\
\hline Algas vermelhas & $\mathrm{R}$ & $\mathrm{R}$ & $\mathrm{F}$ & A A A & A R P & A R F \\
\hline Zoanthus sociatus & $\mathrm{F}$ & $\mathrm{P}$ & $\mathrm{R}$ & A A A & A A A & A A A \\
\hline Fissurelideos & $\mathrm{F}$ & $\mathrm{P}$ & $\mathrm{F}$ & A A A & R R P & R R R \\
\hline Vermetídeos & $\mathrm{P}$ & $\mathrm{F}$ & $\mathrm{R}$ & A A A & A P A & A F A \\
\hline Megaballanus & $\mathrm{P}$ & $\mathrm{F}$ & $\mathrm{P}$ & A A A & A A A & A A A \\
\hline$\overline{\text { Tetraclita }}$ & $\mathrm{P}$ & $\mathrm{F}$ & $\mathrm{R}$ & A A A & A A A & A A A \\
\hline Echinometra lucunter & $\mathrm{P}$ & $\mathrm{P}$ & $\mathrm{P}$ & A A A & A A A & A A A \\
\hline
\end{tabular}

Através dos perfis demarcados perpendicularmente no recife, notou-se a ocorrência de algas verdes, vermelhas e pardas que se distribuem principalmente nas partes mais baixas do recife, sendo mais desenvolvidas na porção externa. Algas coralinas constituem um elemento florístico significativo ao longo dos perfis onde foram encontrados numerosos moluscos fissurelídeos adaptados a viverem expostos ao batimento e atrito provocados pelas ondas de arrebentação. Tanto essas algas como os moluscos citados são menos freqüentes na parte interna, voltada para a baía.. Dentre os demais representantes faunísticos, destaca-se a craca Megaballanus sp e Tetraclita sp. Alguns componentes do bentos estão restritos a determinadas condições, como o ouriço Echinometra lucunter (Linné, 1758), muito freqüente, habitando a superfície do recife em partes mais altas, desde que haja retenção de água pela presença de poças de maré. Observou-se que os organismos bentônicos são mais abundantes na faixa externa e superfície mais elevada do recife, com maior influência de algas marinhas e menor processo de sedimentação que é muito comum na porção interna do recife. Os grupos de distribuição mais homogênea sobre o recife estiveram representados pelas algas coralinas e cracas. Um segundo grupo esteve representado pelos moluscos gastropodos vermetídeos, que participam ativamente na formação do recife. Outros organismos muito comuns estiveram representados pelo Zoanthus sociatus (Ellis, 1767) e algas Gellidium.

As áreas internas do recife apresentaram-se encobertas por sedimentos oriundos de dragagens e vestígios de algas vermelhas e verdes aderidas. Poucos animais estavam fixados, destacando-se cracas Tetraclita e moluscos fissurelídeos. Constatou-se a presença de crustáceos anfípodos associados às algas, bem como crustáceos decápodos de habito errante sobre as mesmas. A dessecação que afeta a comunidade incrustante nas regiões entre-marés é um fator que interfere na distribuição vertical dos organismos ao longo da coluna d’água e, conseqüentemente tem importante influência na composição das comunidades, uma vez que terão sucesso nesses locais 
somente aquelas espécies adaptadas às oscilações dos níveis de maré e suas conseqüências. Coleman (1973) verificou que a taxa de dessecação varia inversamente ao tamanho dos indivíduos. De acordo com Kenedy (1976) os organismos menores são menos tolerantes à dessecação do que os maiores. A presença de algas minimiza o estresse da dessecação, porém pode atrapalhar na captação de alimento. Da mesma forma, superfícies sombreadas aumentam o limite superior das espécies.

Em relação ao substrato, a presença de fendas e falhas em rochas nas regiões entre-marés aumentam a extensão de faixas ocupadas por cada espécie, devido a sua contribuição para a diminuição do estresse da dessecação. Pomerat \& Wisely (1959) experimentaram vários substratos e sugeriram que a sua eficiência como coletora do fouling está relacionada com a porosidade da sua superfície, onde aquelas mais lisas são menos eficientes no recrutamento dos organismos sedentários.

Após dois meses de exposição, os pontos selecionados e raspados na porção interna do recife apresentaram-se encobertos por sedimentos oriundos de dragagens, circundados por algas vermelhas e verdes calcáreas, esta em menor quantidade. Sobre a superfície raspada nenhum organismo macroscópico foi identificado, exceto por alguns componentes da fauna sedentária representadas pelos moluscos gastrópodes fissurelídeos.

O ponto interno situado mais distante das obras de abertura do canal apresentou menor influência da sedimentação o que favoreceu o surgimento de algas filamentosas verdes sobre a superfície raspada, sendo este grupo florístico considerado o Primeiro colonizador da área estudada.

As áreas marcadas na porção média, embora caracteristicamente distintas, estiveram localizadas em pontos semelhantes (ambas sobre a superfície mediana do recife). Estes pontos não apresentaram nenhum vestígio de colonização, embora o primeiro sofresse maior influência da área circunvizinha que está no mesmo nível. A forte sedimentação na região próxima ao novo canal pareceu exercer uma influência negativa sobre a taxa de recobrimento a partir de uma superfície limpa de recife. Uma fina película de algas filamentosas pode ser percebida recobrindo a área em quase toda a sua totalidade. Já no ponto que se posicionou num plano mais elevado do que o recife, por se tratar de um bloco solto, sofreu menos influência das algas circunvizinhas, não sendo evidenciado nenhum sinal de recobrimento.

As áreas, demarcadas na porção interna do recife, foram as que sofreram maior influência da sedimentação. Supostamente, qualquer tentativa de recolonização por parte de algum organismo sobre estas superfícies teve como principal entrave o excesso de partículas trazidas e ali depositadas durante a preamar. A superfície dos dois pontos esteve coberta de lama em toda a sua extensão.

Durante as visitas realizadas no mês de outubro nas áreas demarcadas para o estudo das incrustações biológicas do recife de Suape, procedeu-se as observações sobre a evolução do processo de cobertura incrustante nos pontos escolhidos para acompanhamento. Os pontos posicionados na porção interna do recife apresentaram-se cobertos por uma fina camada de lama, mas foi possível observar a presença de incrustações esparsas de alga filamentosa verde (colonizador primário). Os pontos situados na porção mediana do recife estiveram sujeitos à forte incidência de raios solares, apresentando-se completamente expostos e inundados por ocasião da preamar. Foi constatado que o ponto escolhido para acompanhamento de recolonização apresentou um crescimento algal maior que o descrito anteriormente, encoberto pelas mesmas algas filamentosas verdes, só que com maior densidade. Os pontos situados na porção externa do recife, estiveram sujeitos à forte influência da energia das ondas e, muitas vezes, apresentou-se inundado ou muito úmido, mesmo durante a baixa-mar, estando completa e densamente encoberto predominantemente por algas filamentosas verdes, e em menor proporção, pelas algas pardas.

Após seis meses de exposição (dezembro de 1998), foi constatado um rápido crescimento algal na maioria das áreas demarcadas, o que demonstra um processo de desenvolvimento das 
algas filamentosas verdes como os primeiros colonizadores. No ponto que representou a porção interna mais próxima do canal, a parte interna do recife foi a que demonstrou maior dificuldade de desenvolvimento de aderências orgânicas devido ao intenso processo de sedimentação (o ponto apresentou-se totalmente encoberto por lama). Durante o período de maré alta a superfície do recife interno apareceu coberta por águas turvas devido ao intenso processo de dragagens ocasionadas pelas obras do Porto de Suape. Ali ocorreu sobre esta superfície, um acumulo do sedimento revolvido no fundo da Baía, vindo a impossibilitar qualquer tentativa de fixação por parte dos primeiros colonizadores (algas filamentosas) neste ponto. Como já é de conhecimento, sem a presença dos colonizadores primários, torna-se inviável a formação de aderências por parte de colonizadores tardios. Estas mesmas características puderam ser observadas no ponto interno mais afastado do novo canal de navegação, pois embora mais afastado da região de dragagem, sofreu a influência da sedimentação em decorrência da maré alta e do efeito das correntes marinhas locais.

Após seis meses de observações o ponto na porção média do perfil I do recife mostrou-se perfeitamente coberto pelos organismos das áreas vizinhas, enquanto que a área equivalente no Perfil II não apresentou nenhum sinal de colonização. A forte influência das incrustações em volta do primeiro ponto, associada à constantes inundações por ocasião da maré alta, e a menor influência de sedimentação, foram mais apropriadas à recolonização. Representantes da fauna, contudo, não constituem parte integrante de aderências neste ponto, sedo predominante um rico desenvolvimento de algas filamentosas verdes com um incremento de algas filamentosas pardas, que constitui o segundo degrau do processo de sucessão ecológica neste estudo. Estas mesmas características foram apontadas para as áreas externas do recife.

\section{CONCLUSÕES}

O recife arenítico de Suape, litoral sul de Pernambuco, apresentou-se encoberto por bioincrustações predominantemente florística seguindo os padrões de composição algal encontrados em outros ambientes semelhantes

O intenso processo de sedimentação pelo qual a porção interna e média do recife vinha sofrendo foi o principal agente que dificultou o desenvolvimento e a sucessão das aderências orgânicas.

Os pontos localizados na porção externa do recife, sofreram rápidos processos de desenvolvimento de incrustações devido ao tipo de ambiente que favoreceu o desenvolvimento de algas e organismos adaptados à viver em regiões de intensa energia de ondas.

Os primeiros colonizadores macroscópicos assinalados foram as algas filamentosas verdes, seguidas das algas pardas com eventual surgimento de organismos sedentários raspadores.

\section{REFERÊNCIAS BIBLIOGRÁFICAS}

COE, W. R.; ALLEN, W. E. Growth of sedentary marine organisms on experimental blocks and plates for nine successive year. Bull Scripps Inst. Ocean. Univ. Calif., v. 4, n. 4, p. 101-136. 1937.

COLEMAN, N. Water loss from aerially exposed mussels. J. Exp. Mar. Biol. Ecol., v. 12, p. 145155. 1973.

DAYTON, P. K. Competition, disturbance and community organization: the provision and subsequent utilization of space in a rocky intertidal community. Ecoll. Monogr., v. 41, p. 351389.1971. 
DAYTON, P. K.. Towards na understanding of community resilience and the potential effects of enrichements to the benthos at the McMurdo sound, Antarctica. Proc. Colloquium Cons. Probl. Antart., v. 81-95. 1972.

FERNANDES, M. L. B. Avaliação de dois ambientes recifais do litoral de Pernambuco, através das suas macro e megafaunas incrustantes e sedentárias. São Paulo. 320 p. 2000.. Tese (Doutorado) - Instituto Oceanográfico da Universidade de São Paulo.

GIORDANO, F. Colonizacao de placas de fouling no estuario de Santos (Santos-SP): análises transicional e de sensibilidade complementando a abordagem baseada em recobrimentos especificos e diversidade São Paulo.159p. 2001. Tese (Doutorado). Instituto de Biociências da Universidade de São Paulo.

KENEDY, V. S. Desiccation, higher temperatures and upper intertidal limits of three species of sea mussels (Mollusca: Bivalvia). New Zeland. Mar. Biol., v. 35 p. 127-137.1976.

ORTEGA, S. Environmental stress, competition and dominance of Crassostrea cirginica near Beaufort, North Carolina, USA. Mar. Biol, v.. 62, p. 47-56. 1981.

POMERAT \& WISELY, B. Factors influencing the settling of the principal marine fouling organisms in Sidney Harbour. J. Mar. Freshwater, v. 10, p. 30-44. 1959.

SILVA, S. H. G.; NUNES, A. J. B.; ALVES, M. C. et al. Contribuição ao estudo das comunidades incrustantes que ocorrem na Baía da Guanabara. Revista Brasileira de Biologia. Rio de Janeiro. v. 40, n. 2, p. 367-382. 1980.

STENECK, R. S.; CARLTON, J. T. Human Alterations of Marine Communities: Students Beware! In: Bertness, M; Gaines, S.; Hai, M. (ed.). Marine Community Ecology. Sunderland. 2000, p. 445-468.

STRAUGHAND, D. Intertidal fouling in the Brasibane River. Proc. R. Soc. Queensland, v. 79 n. 4, p. 25-40. 1967. 